\title{
Towards Measure of Semantic Correlation between Messages in Multiagent System
}

\author{
Agnieszka Pieczyńska-Kuchtiak and Radoslaw Katarzyniak \\ Institute of Control and Systems Engineering, Wrocław University of Technology, \\ Wybrzeże Wyspianskiego 27, 50-370 Wrocław, Poland \\ \{agnieszka.pieczynska-kuchtiak, radoslaw.katarzyniak\}@pwr.wroc.pl
}

\begin{abstract}
In this work an original method for the measure of semantic correlation between messages generated by communicative agents in multiagent system is presented. This method is applied to the algorithm for finding the set of agents with the maximal cognitive capacity to observe the states of the objects from external world. It is assumed that the generated messages are the result of the process of language generation, represented by the algorithm for the choice of relevant semantic messages. This algorithm relates belief formulas to the internal agents' knowledge states.
\end{abstract}

\section{Introduction}

In this paper a method for the measure of semantic correlation between messages in multiagent system is presented. It is assumed that each agent $a \in A=\left\{a_{1}, a_{2}, \ldots, a_{z}\right\}$ is situated in a real, ontologically independent world. In this world some objects $\mathrm{O}=\left\{\mathrm{O}_{1}, \mathrm{o}_{2}, \ldots, \mathrm{o}_{\mathrm{S}}\right\}$ exist. States of these objects are a target of the agents' cognitive processes. Each object $\mathrm{o} \in \mathrm{O}$ is described by means of properties from the set $\Delta=\left\{\mathrm{P}_{1}, \mathrm{P}_{2}, \ldots, \mathrm{P}_{\mathrm{K}}\right\}$. In particular, the cognitive agent $\mathrm{a} \in \mathrm{A}=\left\{\mathrm{a}_{1}, \mathrm{a}_{2}, \ldots, \mathrm{a}_{\mathrm{z}}\right\}$ can think of an object $\mathrm{o} \in \mathrm{O}$ as having or not having a particular property $\mathrm{P} \in \Delta$. Perceptions collected by the agents are ordered in relation to a line of time points $T=\left\{t_{0}, t_{1}, t_{2}, ..\right\}$ [9]. Each agent is equipped with the communication language, which makes it possible for an agent to generate the logic formulas. Each formula is interpreted from the agent's point of view as external, logical representation of beliefs on current state of the object. Each formula is built of the modal operator of belief, two names of the properties and logic operator of belief. The scope of the agents' language is given in a Table 1.

The basic assumption is that, if an agent can not observe the current state of the particular object, then he refers to the overall private knowledge and applies dedicated algorithm for the choice of relevant semantic messages. This algorithm, which reflects the process of symbol grounding, applies a new and alternative approach to define the epistemic concept of belief. The symbol grounding is understood as a mental phenomenon that assigns meaning to language and relates language symbols to the external objects in a very certain way [5], [7], [8]. The algorithm for the choice of relevant messages relates belief formulas to internal representations of an object rather than to ontologically existing entity. In consequence each formula is treated by 
Table 1. Language messages

\begin{tabular}{|c|c|c|}
\hline & $\begin{array}{c}\text { Formal } \\
\text { Abbreviations }\end{array}$ & Spoken Language Interpretation \\
\hline (1) & $\mathrm{B}^{\mathrm{a}}\left(\mathrm{P}_{\mathrm{i}}(\mathrm{o}) \wedge \mathrm{P}_{\mathrm{j}}(\mathrm{o})\right)$ & $\begin{array}{l}\text { I (agent a) believe that object o has the } \\
\text { property } \mathrm{P}_{\mathrm{i}} \text { and the property } \mathrm{P}_{\mathrm{i}} \text {. }\end{array}$ \\
\hline$(2)$ & $\mathrm{B}^{\mathrm{a}}\left(\mathrm{P}_{\mathrm{i}}(\mathrm{o}) \wedge \neg \mathrm{P}_{\mathrm{j}}(\mathrm{o})\right)$ & $\begin{array}{l}\text { I (agent a) believe that object o has the } \\
\text { property } \mathrm{P}_{\mathrm{i}} \text { and does not have the property } \mathrm{P}_{\text {. }} \text {. }\end{array}$ \\
\hline (3) & $\mathrm{B}^{\mathrm{a}}\left(\neg \mathrm{P}_{\mathrm{i}}(\mathrm{o}) \wedge \mathrm{P}_{\mathrm{j}}(\mathrm{o})\right)$ & $\begin{array}{l}\text { I (agent a) believe that object o does not have } \\
\text { the property } \mathrm{P}_{\mathrm{i}} \text { and has the property } \mathrm{P}_{\mathrm{j}} \text {. }\end{array}$ \\
\hline (4) & $\mathrm{B}^{\mathrm{a}}\left(\neg \mathrm{P}_{\mathrm{i}}(\mathrm{o}) \wedge \neg \mathrm{P}_{\mathrm{j}}(\mathrm{o})\right)$ & $\begin{array}{l}\text { I (agent a) believe that object o does not have } \\
\text { the property } P_{i} \text { and the property } P_{j} \text {. }\end{array}$ \\
\hline$(5)$ & $\mathrm{B}^{\mathrm{a}}\left(\mathrm{P}_{\mathrm{i}}(\mathrm{o}) \underline{\vee}_{\mathrm{j}}(\mathrm{o})\right)$ & $\begin{array}{l}\text { I (agent a) believe that object o has either the } \\
\text { property } \mathrm{P}_{\mathrm{i}} \text { or the property } \mathrm{P}_{\mathrm{j}} \text {. }\end{array}$ \\
\hline (6) & $\mathrm{B}^{\mathrm{a}}\left(\mathrm{P}_{\mathrm{i}}(\mathrm{o}) \vee \mathrm{P}_{\mathrm{j}}(\mathrm{o})\right)$ & $\begin{array}{l}\text { I (agent a) believe that object o has the } \\
\text { property } \mathrm{P}_{\mathrm{i}} \text { or the property } \mathrm{P}_{\mathrm{j}} \text {. }\end{array}$ \\
\hline
\end{tabular}

the cognitive agent as true, if and only if this formula is satisfied by the overall state of agent encapsulated knowledge. Such an approach to understanding satisfaction relation is alternative to the commonly known extensional definition of the satisfaction formulas accepted within Tarskian theory of truth [7]. In this sense the algorithm realises an original way of semantic and interpreted language generation. The aim of this paper is to investigate the level of formula grounding by measure of semantic closeness of the messages, which are generated individually by the agents using the algorithm for the choice of relevant messages. It is assumed that these formulas are syntactically identical. The question is: if the semantic of these formulas is also identical. We want to compare the states of agents knowledge which let them generate such formulas. As a result of this comparison the set of agents with the maximal cognitive capacity to observe the states of objects and maximal similarity of knowledge states to the median state of knowledge of all the agents is computed.

\section{Basic Notions}

The state of the external world, recognised by the agent $\mathrm{a} \in \mathrm{A}$ at the particular time point $\mathrm{t}_{\mathrm{n}}$ is represented in its body as a base profile and is given as:

$$
\mathrm{BP}^{\mathrm{a}}\left(\mathrm{t}_{\mathrm{n}}\right)=<\mathrm{O}, \mathrm{P}_{1}^{+}\left(\mathrm{t}_{\mathrm{n}}\right), \mathrm{P}_{1}^{-}\left(\mathrm{t}_{\mathrm{n}}\right), \mathrm{P}_{1}^{ \pm}\left(\mathrm{t}_{\mathrm{n}}\right), \ldots, \mathrm{P}_{\mathrm{K}}^{+}\left(\mathrm{t}_{\mathrm{n}}\right), \mathrm{P}_{\mathrm{K}}^{-}\left(\mathrm{t}_{\mathrm{n}}\right), \mathrm{P}_{\mathrm{K}}^{ \pm}\left(\mathrm{t}_{\mathrm{n}}\right)>
$$

Remark 1. $\mathrm{O}=\left\{\mathrm{o}_{1}, \mathrm{o}_{2}, \ldots, \mathrm{o}_{\mathrm{S}}\right\}$ and each o denotes a unique cognitive representation of a particular object of the external world $\mathrm{W}$.

Remark 2. For $\mathrm{i}=1,2, \ldots, \mathrm{K}, \mathrm{P}^{+}{ }_{\mathrm{j}}\left(\mathrm{t}_{\mathrm{n}}\right) \subseteq \mathrm{O}$ and $\mathrm{P}^{-}{ }_{\mathrm{j}}\left(\mathrm{t}_{\mathrm{n}}\right) \subseteq \mathrm{O}$. For each $\mathrm{o} \in \mathrm{O}$ the relation $\mathrm{o} \in \mathrm{P}^{+}{ }_{\mathrm{i}}\left(\mathrm{t}_{\mathrm{n}}\right)$ holds if and only if the agent has perceived that this object o possesses atomic property $\mathrm{P}_{\mathrm{i}}$. For each $\mathrm{o} \in \mathrm{O}$ the relation $\mathrm{o} \in \mathrm{P}^{-}{ }_{\mathrm{i}}\left(\mathrm{t}_{\mathrm{n}}\right)$ holds if and only if the agent has perceived that this object o does not posses the atomic property $\mathrm{P}_{\mathrm{i}}$. 
Remark 3. The set of objects $\mathrm{P}^{ \pm}{ }_{\mathrm{i}}\left(\mathrm{t}_{\mathrm{k}}\right)=\mathrm{O} /\left(\mathrm{P}^{+}{ }_{\mathrm{i}}\left(\mathrm{t}_{\mathrm{k}}\right) \cup \mathrm{P}^{-}{ }_{\mathrm{i}}\left(\mathrm{t}_{\mathrm{k}}\right)\right)$ is called the area of agent's incompetence related to the property $\mathrm{P}_{\mathrm{i}}$. For each $\mathrm{o} \in \mathrm{O}$ the relation $\mathrm{o} \in \mathrm{P}^{ \pm}{ }_{\mathrm{i}}\left(\mathrm{t}_{\mathrm{n}}\right)$ holds if and only if the agent could not perceive the state of this object $\mathrm{o}$ in relation to the property $\mathrm{P}_{\mathrm{i}}$.

The overall state of perceptions, stored by the agent $\mathrm{a} \in \mathrm{A}$, is given as a temporal data base consisted of the set of base profiles:

$$
\mathrm{KS}^{\mathrm{a}}\left(\mathrm{t}_{\mathrm{c}}\right)=\left\{B \mathrm{PP}^{\mathrm{a}}\left(\mathrm{t}_{\mathrm{n}}\right): \mathrm{t}_{\mathrm{n}} \in \mathrm{T} \text { and } \mathrm{t}_{\mathrm{n}} \leq \mathrm{t}_{\mathrm{c}}\right\},
$$

where $t_{n}, t_{c}$ are time points.

\section{The Idea of an Algorithm for the Choice of Relevant Messages}

In this section the idea of an algorithm for the choice of relevant semantic messages is explained. Understanding the essence of this algorithm is a key point in understanding the method for the measure semantic correlation between messages, discussed in Section 4. It is assumed, that at the time point $t_{c}$ the state of an object $o \in O$ in relation to the properties $\mathrm{P}_{\mathrm{i}}$ and $\mathrm{P}_{\mathrm{j}}$ for at least two agents is not known and can not be verified by sensing:

$$
\forall \mathrm{PB}^{\mathrm{a}}\left(\mathrm{t}_{\mathrm{c}}\right) \in \mathrm{KS}^{\mathrm{a}}\left(\mathrm{t}_{\mathrm{c}}\right) .\left(\mathrm{o} \in \mathrm{P}^{ \pm}{ }_{\mathrm{i}}\left(\mathrm{t}_{\mathrm{c}}\right) \text { and } \mathrm{o} \in \mathrm{P}^{ \pm}{ }_{\mathrm{j}}\left(\mathrm{t}_{\mathrm{c}}\right)\right) \text { for } \mathrm{a} \in \mathrm{A}^{\prime} \subseteq \mathrm{A} \text {, } \operatorname{card}\left(\mathrm{A}^{\prime}\right)>1, \mathrm{i}, \mathrm{j} \in \mathrm{K}
$$

where $A^{\prime}$ denotes the set of agents, that can not observe the state of an object $\mathrm{o}$ in relation to the properties $\mathrm{P}_{\mathrm{i}}$ and $\mathrm{P}_{\mathrm{j}}$.

All experiences, internally stored by each agent, represented by $\mathrm{KS}^{\mathrm{a}}\left(\mathrm{t}_{\mathrm{c}}\right), \mathrm{a} \in \mathrm{A}^{\prime}$, are the source of a meaning for the external formulas. The algorithm for the choice of relevant semantic messages is consisted of five steps [9], [10], [11]:

Step1. Message oriented classification of perceptions. The procedure for applying all stored perceptions uses a simple classification of empirical content in $\mathrm{KS}\left(\mathrm{t}_{\mathrm{k}}\right)$. In particular, the following classes of base profiles are taken into account:

a) $\mathrm{C}_{1}^{\mathrm{a}}\left(\mathrm{t}_{\mathrm{c}}\right)=\left\{\mathrm{BP}^{\mathrm{a}}\left(\mathrm{t}_{\mathrm{n}}\right): \mathrm{a} \in \mathrm{A}^{\prime}, \mathrm{t}_{\mathrm{n}} \leq \mathrm{t}_{\mathrm{c}}, \mathrm{BP}^{\mathrm{a}}\left(\mathrm{t}_{\mathrm{n}}\right) \in \mathrm{KS}^{\mathrm{a}}\left(\mathrm{t}_{\mathrm{c}}\right)\right.$ and both $\mathrm{o} \in \mathrm{P}^{+}{ }_{\mathrm{i}}\left(\mathrm{t}_{\mathrm{n}}\right)$ and $\mathrm{o} \in \mathrm{P}^{+}{ }_{\mathrm{j}}\left(\mathrm{t}_{\mathrm{n}}\right)$ hold for $\left.\operatorname{BP}^{\mathrm{a}}\left(\mathrm{t}_{\mathrm{n}}\right)\right\}$

Obviously, this class of data consists of all base profiles stored up to the time point $t_{c}$, in which the object o has been found by the agent a as having both properties $\mathrm{P}^{+}{ }_{\mathrm{i}}$ and $\mathrm{P}^{+}$.

b) $\mathrm{C}_{2}^{\mathrm{a}}\left(\mathrm{t}_{\mathrm{c}}\right)=\left\{\mathrm{BP}^{\mathrm{a}}\left(\mathrm{t}_{\mathrm{n}}\right): \mathrm{a} \in \mathrm{A}^{\prime}, \mathrm{t}_{\mathrm{n}} \leq \mathrm{t}_{\mathrm{c}}, \mathrm{BP}^{\mathrm{a}}\left(\mathrm{t}_{\mathrm{n}}\right) \in \mathrm{KS}^{\mathrm{a}}\left(\mathrm{t}_{\mathrm{c}}\right)\right.$ and both $\mathrm{o} \in \mathrm{P}^{+}\left(\mathrm{t}_{\mathrm{n}}\right)$ and $\mathrm{o} \in \mathrm{P}^{-}{ }_{\mathrm{j}}\left(\mathrm{t}_{\mathrm{n}}\right)$ hold for $\left.\mathrm{BP}^{\mathrm{a}}\left(\mathrm{t}_{\mathrm{n}}\right)\right\}$

c) $\mathrm{C}_{3}^{\mathrm{a}}\left(\mathrm{t}_{\mathrm{c}}\right)=\left\{\mathrm{BP}^{\mathrm{a}}\left(\mathrm{t}_{\mathrm{n}}\right): \mathrm{a} \in \mathrm{A}^{\prime}, \mathrm{t}_{\mathrm{n}} \leq \mathrm{t}_{\mathrm{c}}, \mathrm{BP}^{\mathrm{a}}\left(\mathrm{t}_{\mathrm{n}}\right) \in \mathrm{KS}^{\mathrm{a}}\left(\mathrm{t}_{\mathrm{c}}\right)\right.$ and both $\mathrm{o} \in \mathrm{P}^{-}{ }_{\mathrm{i}}\left(\mathrm{t}_{\mathrm{n}}\right)$ and $\mathrm{o} \in \mathrm{P}^{+}{ }_{\mathrm{j}}\left(\mathrm{t}_{\mathrm{n}}\right)$ hold for $\left.\mathrm{BP}^{\mathrm{a}}\left(\mathrm{t}_{\mathrm{n}}\right)\right\}$

d) $\mathrm{C}_{4}^{\mathrm{a}}\left(\mathrm{t}_{\mathrm{c}}\right)=\left\{\mathrm{BP}^{\mathrm{a}}\left(\mathrm{t}_{\mathrm{n}}\right): \mathrm{a} \in \mathrm{A}^{\prime}, \mathrm{t}_{\mathrm{n}} \leq \mathrm{t}_{\mathrm{c}}, \mathrm{BP}^{\mathrm{a}}\left(\mathrm{t}_{\mathrm{n}}\right) \in \mathrm{KS}^{\mathrm{a}}\left(\mathrm{t}_{\mathrm{c}}\right)\right.$ and both $\mathrm{o} \in \mathrm{P}^{-}{ }_{\mathrm{i}}\left(\mathrm{t}_{\mathrm{n}}\right)$ and $\mathrm{o} \in \mathrm{P}^{-}{ }_{\mathrm{j}}\left(\mathrm{t}_{\mathrm{n}}\right)$ hold for $\left.\mathrm{BP}^{\mathrm{a}}\left(\mathrm{t}_{\mathrm{n}}\right)\right\}$

Interpretations for $\mathrm{C}_{2}^{\mathrm{a}}\left(\mathrm{t}_{\mathrm{c}}\right), \mathrm{C}_{3}^{\mathrm{a}}\left(\mathrm{t}_{\mathrm{c}}\right)$ and $\mathrm{C}_{4}^{\mathrm{a}}\left(\mathrm{t}_{\mathrm{c}}\right)$ are similar to $\mathrm{C}_{1}^{\mathrm{a}}\left(\mathrm{t}_{\mathrm{c}}\right)$.

The importance of $\mathrm{C}_{1}^{\mathrm{a}}\left(\mathrm{t}_{\mathrm{c}}\right), \mathrm{C}_{2}^{\mathrm{a}}\left(\mathrm{t}_{\mathrm{c}}\right), \mathrm{C}_{3}^{\mathrm{a}}\left(\mathrm{t}_{\mathrm{c}}\right)$ and $\mathrm{C}_{4}^{\mathrm{a}}\left(\mathrm{t}_{\mathrm{c}}\right)$ for the choice of relevant messages results from the semantic relations given in Table 2 (see also [5], [8]). 
Table 2. Semantic correlation between external formulas and classes of perceptions

$\mathrm{B}^{\mathrm{a}}\left(\mathrm{P}_{\mathrm{i}}(\mathrm{o}) \wedge \mathrm{P}_{\mathrm{j}}(\mathrm{o})\right)$ is related to the content of $\mathrm{C}_{1}^{\mathrm{a}}\left(\mathrm{t}_{\mathrm{c}}\right)$
$\mathrm{B}^{\mathrm{a}}\left(\mathrm{P}_{\mathrm{i}}(\mathrm{o}) \wedge \neg \mathrm{P}_{\mathrm{j}}(\mathrm{o})\right)$ is related to the content of $\mathrm{C}^{\mathrm{a}}\left(\mathrm{t}_{\mathrm{c}}\right)$
$\mathrm{B}^{\mathrm{a}}\left(\neg \mathrm{P}_{\mathrm{i}}(\mathrm{o}) \wedge \mathrm{P}_{\mathrm{j}}(\mathrm{o})\right)$ is related to the content of $\mathrm{C}_{3}^{\mathrm{a}}\left(\mathrm{t}_{\mathrm{c}}\right)$
$\mathrm{B}^{\mathrm{a}}\left(\neg \mathrm{P}_{\mathrm{i}}(\mathrm{o}) \wedge \neg \mathrm{P}_{\mathrm{j}}(\mathrm{o})\right)$ is related to the content of $\mathrm{C}_{4}^{\mathrm{a}}\left(\mathrm{t}_{\mathrm{c}}\right)$
$\mathrm{B}^{\mathrm{a}}\left(\mathrm{P}_{\mathrm{i}}(\mathrm{o}) \vee \mathrm{P}_{\mathrm{j}}(\mathrm{o})\right)$ is related to the content of $\mathrm{C}_{5}^{\mathrm{a}}\left(\mathrm{t}_{\mathrm{c}}\right)=\mathrm{C}_{2}^{\mathrm{a}}\left(\mathrm{t}_{\mathrm{c}}\right) \cup \mathrm{C}_{3}^{\mathrm{a}}\left(\mathrm{t}_{\mathrm{c}}\right)$
$\mathrm{B}^{\mathrm{a}}\left(\mathrm{P}_{\mathrm{i}}(\mathrm{o}) \vee \mathrm{P}_{\mathrm{j}}(\mathrm{o})\right)$ is related to the content of $\mathrm{C}_{6}^{\mathrm{a}}{ }_{6}\left(\mathrm{t}_{\mathrm{c}}\right)=\mathrm{C}_{1}{ }_{1}\left(\mathrm{t}_{\mathrm{c}}\right) \cup \mathrm{C}_{2}^{\mathrm{a}}\left(\mathrm{t}_{\mathrm{c}}\right) \cup \mathrm{C}_{3}^{\mathrm{a}}\left(\mathrm{t}_{\mathrm{c}}\right)$

Step 2. A unique representative $\mathrm{CBP}_{\mathrm{m}}^{\mathrm{a}}\left(\mathrm{t}_{\mathrm{c}}\right), \mathrm{m}=1,2,3,4$ of all perceptions stored in $\mathrm{C}_{\mathrm{m}}^{\mathrm{a}}\left(\mathrm{t}_{\mathrm{k}}\right)$ is computed. The structure $\mathrm{CPB}_{\mathrm{m}}^{\mathrm{a}}\left(\mathrm{t}_{\mathrm{c}}\right)$ is given as a consensus profile and interpreted as the agreement on the overall knowledge stored in a particular class $\mathrm{C}_{\mathrm{m}}^{\mathrm{a}}\left(\mathrm{t}_{\mathrm{k}}\right)$. Obviously, from the formal point of view the consensus $\mathrm{CBP}_{\mathrm{m}}^{\mathrm{a}}\left(\mathrm{t}_{\mathrm{c}}\right)$ from $\mathrm{C}_{\mathrm{m}}^{\mathrm{a}}\left(\mathrm{t}_{\mathrm{k}}\right) \subseteq \mathrm{KS}\left(\mathrm{t}_{\mathrm{c}}\right), \mathrm{m}=1,2,3,4$ is given as:

$$
\mathrm{CBP}_{\mathrm{m}}^{\mathrm{a}}\left(\mathrm{t}_{\mathrm{c}}\right)=\left\langle\mathrm{O}, \mathrm{cP}_{1}^{+}\left(\mathrm{t}_{\mathrm{n}}\right), \mathrm{cP}_{1}^{-}\left(\mathrm{t}_{\mathrm{n}}\right), \mathrm{cP}_{1}^{ \pm}\left(\mathrm{t}_{\mathrm{n}}\right), \ldots, \mathrm{cP}_{\mathrm{K}}^{+}\left(\mathrm{t}_{\mathrm{n}}\right), \mathrm{cP}_{\mathrm{K}}^{-}\left(\mathrm{t}_{\mathrm{n}}\right), \mathrm{cP}_{\mathrm{K}}^{ \pm}\left(\mathrm{t}_{\mathrm{n}}\right)\right\rangle
$$

On this stage of algorithm the knowledge representation in the form of the base profiles is transformed to the single profile.

In order to determine $\mathrm{CPB}_{\mathrm{m}}^{\mathrm{a}}\left(\mathrm{t}_{\mathrm{c}}\right)$ some rational requirements need to be fulfilled. Examples of the sets of requirements, postulates and algorithms based on these postulates are given in [6].

Step 3. For each $\mathrm{m}=1,2,3,4$ the agent a computes the distance $\mathrm{d}_{\mathrm{m}}^{\mathrm{a}}$ between $\mathrm{CBP}_{\mathrm{m}}^{\mathrm{a}}\left(\mathrm{t}_{\mathrm{c}}\right)$ and the current profile $\mathrm{BP}^{\mathrm{a}}\left(\mathrm{t}_{\mathrm{c}}\right)$. This distance reflects the numerical similarity between each set $C_{m}^{a}\left(t_{c}\right), \mathrm{m}=1,2,3,4$ and the current base profile $\mathrm{PB}_{\mathrm{m}}^{\mathrm{a}}\left(\mathrm{t}_{\mathrm{c}}\right)$. An original approach to computing this type of measure is given in [9].

Step 4. The agent a computes a choice function values $\mathrm{V}_{\mathrm{m}}^{\mathrm{a}}(\mathrm{X}), \mathrm{m}=1, \ldots, 6$. Each of these values is derived from a subset of $\left\{\mathrm{d}_{1}, \mathrm{~d}_{2}, \mathrm{~d}_{3}, \mathrm{~d}_{4}\right\}$ relevant to a particular message from Table 1 . The rules for determining decision values are:

$\mathrm{V}_{1}^{\mathrm{a}}(\mathrm{X})$ is derived for $\mathrm{B}^{\mathrm{a}}\left(\mathrm{P}_{\mathrm{i}}(\mathrm{o}) \wedge \mathrm{P}_{\mathrm{j}}(\mathrm{o})\right)$ from the set of distances $\mathrm{X}=\left\{\mathrm{d}_{1}\right\}$ $V_{2}^{a}(X)$ is derived for $B^{a}\left(P_{i}(o) \wedge \neg P_{j}(o)\right)$ from the set of distances $X=\left\{d_{2}\right\}$

$V_{3}^{a}(X)$ is derived for $B^{a}\left(\neg P_{i}(o) \wedge P_{j}(o)\right)$ from the set of distances $X=\left\{d_{3}\right\}$

$\mathrm{V}_{4}^{\mathrm{a}}(\mathrm{X})$ is derived for $\mathrm{B}^{\mathrm{a}}\left(\neg \mathrm{P}_{\mathrm{i}}(\mathrm{o}) \wedge \neg \mathrm{P}_{\mathrm{j}}(\mathrm{o})\right)$ from the set of distances $\mathrm{X}=\left\{\mathrm{d}_{4}\right\}$

$V_{5}^{a}(X)$ is derived for $B^{a}\left(P_{i}(o) \underline{v} P_{j}(o)\right)$ from the set of distances $X=\left\{d_{2}, d_{3}\right\}$

$V_{6}{ }_{6}(X)$ is derived for $B^{a}\left(P_{i}(o) \vee P_{j}(o)\right)$ from the set of distances $X=\left\{d_{1}, d_{2}, d_{3}\right\}$

Obviously, the choice of the subset of $\left\{\mathrm{d}_{1}, \mathrm{~d}_{2}, \mathrm{~d}_{3}, \mathrm{~d}_{4}\right\}$ is strictly related to this part of $\mathrm{KS}^{\mathrm{a}}\left(\mathrm{t}_{\mathrm{c}}\right)$ to which a considered message is related. The choice function and some requirements, which should be fulfilled by this function are discussed in details in [12].

Step 5. The message is chosen by the agent a as externally appropriate, for which the decision value $\mathrm{V}_{\mathrm{m}}^{\mathrm{a}}(\mathrm{X})$ is maximal. 


\section{The Semantic Correlation between Messages}

As a result of applying an algorithm for the choice of relevant semantic messages, described in Section 3, each agent $\mathrm{a} \in \mathrm{A}^{\prime} \subseteq \mathrm{A}$ generates one belief formula about the current state of an object $o \in \mathrm{O}$. It is assumed that all of these formulas are syntactically identical. Now we want to find out if the semantics of these formulas are also the same. It is assumed that from the agent's point of view stored perceptions are the original source of any meaning accessible for cognitive processes of symbol grounding. The assumptions about the meaning of formulas is closed to the phenomenological approach to analysis of meaning in which the meaning of any language symbol can ever be reduced by the cognitive agent to reflections of basic empirical data. Each formula is treated as an external reflection of agent's internal knowledge state. In other words, the only meaning that can ever be assigned by the cognitive agent to language symbols (formulas) comes out of the content of remembered experiences [11]. In this context of meaning it might be possible that one belief formula for two agents means completely different. In this paper we propose the method for the measure semantic correlation between messages. This method is applied to the algorithm for finding the set $\mathrm{R}$ of agents with the maximal cognitive capacity to observe the states of objects and maximal similarity of knowledge state to the median state of knowledge. In this algorithm called the algorithm for finding the set of knowledge richest and reliable agents (KRRA), the consensus profiles $\mathrm{CPB}_{\mathrm{m}}^{\mathrm{a}}(\mathrm{tc}), \mathrm{a} \in \mathrm{A}^{\prime}, \mathrm{m} \in\{1,2,3,4\}$ for classes of perception $\mathrm{C}_{\mathrm{m}}^{\mathrm{a}}\left(\mathrm{t}_{\mathrm{c}}\right)$ semantically correlated with external formula (see Table 2) are taken into account.

\subsection{The Idea of KRRA}

Let idea of an algorithm KRRA can be described as follows:

Step 1. Determine the set $\mathrm{CPB}^{\mathrm{A}^{\prime}}{ }_{\mathrm{r}}(\mathrm{t}), \mathrm{r} \in\{1,2, \ldots, 6\}$ of consensus profiles semantically related with the external formulas generated by the agents from the set $A^{\prime}$. Each formula has its tag name (see Table 1) and depending on the external formula generated by each agent $a \in A^{\prime}$ the proper set of base profiles is determined. In particular, the following sets of base profiles are taken into account:

a) $\mathrm{CPB}^{\mathrm{A}^{\prime}}{ }_{1}\left(\mathrm{t}_{\mathrm{c}}\right)=\left\{\mathrm{CBP}_{1}^{\mathrm{a}}\left(\mathrm{t}_{\mathrm{c}}\right): \mathrm{a} \in \mathrm{A}^{\prime}\right\}$

b) $\mathrm{CPB}_{2}{ }^{\mathrm{A}^{\prime}}\left(\mathrm{t}_{\mathrm{c}}\right)=\left\{\mathrm{CBP}_{2}^{\mathrm{a}}\left(\mathrm{t}_{\mathrm{c}}\right): \mathrm{a} \in \mathrm{A}^{\prime}\right\}$

c) $\mathrm{CPB}_{3}^{\mathrm{A}^{\prime}}\left(\mathrm{t}_{\mathrm{c}}\right)=\left\{\mathrm{CBP}_{3}^{\mathrm{a}}\left(\mathrm{t}_{\mathrm{c}}\right): \mathrm{a} \in \mathrm{A}^{\prime}\right\}$

d) $\mathrm{CPB}^{\mathrm{A}^{\prime}}{ }_{4}\left(\mathrm{t}_{\mathrm{c}}\right)=\left\{\mathrm{CBP}_{4}^{\mathrm{a}}\left(\mathrm{t}_{\mathrm{c}}\right): \mathrm{a} \in \mathrm{A}^{\prime}\right\}$

e) $\mathrm{CPB}^{\mathrm{A}^{\prime}}{ }_{5}\left(\mathrm{t}_{\mathrm{c}}\right)=\left\{\mathrm{CBP}^{\mathrm{a}}\left(\mathrm{t}_{\mathrm{c}}\right): \mathrm{a} \in \mathrm{A}^{\prime}\right.$ and $\left.\mathrm{k}=2,3\right\}$

f) $\mathrm{CPB}^{\mathrm{A}^{\prime}}{ }_{6}\left(\mathrm{t}_{\mathrm{c}}\right)=\left\{\mathrm{CBP}^{\mathrm{a}}{ }_{\mathrm{k}}\left(\mathrm{t}_{\mathrm{c}}\right): \mathrm{a} \in \mathrm{A}^{\prime}\right.$ and $\left.\mathrm{k}=1,2,3\right\}$

Step 2. For the set $\mathrm{CPB}^{\mathrm{A}^{\prime}}\left(\mathrm{t}_{\mathrm{c}}\right), \mathrm{r} \in\{1,2, \ldots, 6\}$ compute the median profile $\operatorname{Med}_{{ }_{\mathrm{r}}}^{\mathrm{A}^{\prime}}\left(\mathrm{t}_{\mathrm{c}}\right)$, $\mathrm{r} \in\{1,2, \ldots, 6\}$. Median profile is interpreted as the agreement of the overall knowledge stored in a particular set $\mathrm{CPB}^{\mathrm{A}^{\prime}}{ }_{\mathrm{r}}\left(\mathrm{t}_{\mathrm{c}}\right)$ and has the same structure as consensus profile $\mathrm{CPB}_{\mathrm{m}}^{\mathrm{a}}\left(\mathrm{t}_{\mathrm{c}}\right), \mathrm{m} \in\{1,2,3,4\}$ and consists of the following sets: $\operatorname{medP^{+}}{ }_{\mathrm{i}}\left(\mathrm{t}_{\mathrm{n}}\right), \operatorname{medP}^{-}\left(\mathrm{t}_{\mathrm{n}}\right)$, 
$\operatorname{medP}^{ \pm}{ }_{i}\left(t_{n}\right), i \in\{1,2, \ldots, K\}$. The distance between median profile $\operatorname{Med}^{A^{\prime}}{ }_{r}\left(t_{c}\right)$ and each consensus profile $\mathrm{CPB}^{\mathrm{a}}{ }_{\mathrm{m}}\left(\mathrm{t}_{\mathrm{c}}\right) \in \mathrm{CPB}^{\mathrm{A}^{\prime}}{ }_{\mathrm{r}}\left(\mathrm{t}_{\mathrm{c}}\right), \mathrm{a} \in \mathrm{A}^{\prime}$, must be minimal. For the defined distance function $\mathrm{d}\left(\mathrm{Med}^{\mathrm{A}_{\mathrm{P}}}{ }_{\mathrm{r}}\left(\mathrm{t}_{\mathrm{c}}\right), \mathrm{CPB}_{\mathrm{m}}^{\mathrm{a}}{ }_{\mathrm{m}}\left(\mathrm{t}_{\mathrm{c}}\right)\right)$ holds [13]:

$$
\mathrm{CPB}_{\mathrm{m}}^{\mathrm{a}}\left(\mathrm{t}_{\mathrm{c}}\right) \in \mathrm{CPB}_{\mathrm{r}}^{\mathrm{A}^{\prime}\left(\mathrm{t}_{\mathrm{c}}\right)} \mathrm{d}\left(\operatorname{Med}_{\mathrm{r}}^{\mathrm{A}^{\prime}}\left(\mathrm{t}_{\mathrm{c}}\right), \mathrm{CPB}_{\mathrm{m}}^{\mathrm{a}}\left(\mathrm{t}_{\mathrm{c}}\right)\right)=\operatorname{Min}
$$

where Min is the minimum of all $\mathrm{d}\left(\operatorname{Med}^{\mathrm{A}^{\prime}}{ }_{\mathrm{r}}\left(\mathrm{t}_{\mathrm{c}}\right), \mathrm{CPB}_{\mathrm{m}}^{\mathrm{a}}\left(\mathrm{t}_{\mathrm{c}}\right)\right) \in \mathrm{D}_{\text {Universe }}$, for $\operatorname{Med}_{{ }_{r}}^{\mathrm{A}^{\prime}}\left(\mathrm{t}_{\mathrm{c}}\right) \in \operatorname{Med}_{\text {Universe }}, \quad r \in\{1,2, \ldots 6\}$ and $\operatorname{CPB}^{\mathrm{a}}{ }_{\mathrm{m}}\left(\mathrm{t}_{\mathrm{c}}\right) \in \mathrm{CPB}^{\mathrm{A}^{\prime}}\left(\mathrm{t}_{\mathrm{c}}\right), \quad \mathrm{m} \in\{1, \ldots, 4\} . \operatorname{Med}_{\text {Universe }}$ denotes the universe of all median profiles, $\mathrm{D}_{\text {Universe }}$ is the universe of all distance function values between each median profile from the set $\operatorname{Med}_{\text {Universe }}$ and each consensus profile form the set $\mathrm{CPB}_{\mathrm{m}}^{\mathrm{A}^{\prime}}\left(\mathrm{t}_{\mathrm{c}}\right)$.

Step 3. For each consensus profile $\mathrm{CPB}^{\mathrm{a}}{ }_{\mathrm{m}}\left(\mathrm{t}_{\mathrm{c}}\right) \in \mathrm{CPB}^{\mathrm{A}^{\prime}}{ }_{\mathrm{r}}\left(\mathrm{t}_{\mathrm{c}}\right), \mathrm{r} \in\{1,2, \ldots, 6\}$, compute the value $\mathrm{D}_{\mathrm{a}}^{\mathrm{MC}}=\operatorname{card}\left(\mathrm{MC}_{\mathrm{a}}\right)$ :

$$
\mathrm{MC}_{\mathrm{a}}=\left(\operatorname{medP}_{\mathrm{i}}^{+}\left(\mathrm{t}_{\mathrm{c}}\right) \backslash \mathrm{cP}_{\mathrm{i}}^{+}\left(\mathrm{t}_{\mathrm{c}}\right)\right) \cup\left(\operatorname{medP}_{\mathrm{i}}^{-}\left(\mathrm{t}_{\mathrm{c}}\right) \backslash \mathrm{cP} \mathrm{P}_{\mathrm{i}}^{-}\left(\mathrm{t}_{\mathrm{c}}\right)\right)
$$

where medP ${ }_{i}^{+}\left(t_{c}\right), \operatorname{medP}_{i}^{-}\left(t_{c}\right) \in \operatorname{Med}_{r}{ }_{r}{ }_{r}\left(t_{c}\right)$ and $\mathrm{cP}^{+}{ }_{i}\left(t_{c}\right), \mathrm{cP}^{-}{ }_{i}\left(t_{c}\right) \in \mathrm{CPB}^{\mathrm{a}}{ }_{\mathrm{m}}\left(\mathrm{t}_{\mathrm{c}}\right), \mathrm{m}=1, \ldots, 4$. The aim of this step is to find the consensus profile closest to the median profile.

Step 4. For each consensus profile $\mathrm{CPB}^{\mathrm{a}}{ }_{\mathrm{m}}\left(\mathrm{t}_{\mathrm{c}}\right) \in \mathrm{CPB}^{\mathrm{A}^{\prime}}{ }_{\mathrm{r}}\left(\mathrm{t}_{\mathrm{c}}\right), \mathrm{r} \in\{1,2, \ldots, 6\}$, compute the value $\mathrm{D}_{\mathrm{a}}^{\mathrm{CM}}=\operatorname{card}\left(\mathrm{CM}_{\mathrm{a}}\right)$, where the set $\mathrm{CM}_{\mathrm{a}}$ is equal:

$$
\mathrm{CM}_{\mathrm{a}}=\left(\mathrm{cP}_{\mathrm{i}}^{+}\left(\mathrm{t}_{\mathrm{c}}\right) \backslash \operatorname{medP}_{\mathrm{i}}^{+}\left(\mathrm{t}_{\mathrm{c}}\right)\right) \cup\left(\mathrm{cP}_{\mathrm{i}}^{-}\left(\mathrm{t}_{\mathrm{c}}\right) \backslash \operatorname{medP}_{\mathrm{i}}^{-}\left(\mathrm{t}_{\mathrm{c}}\right)\right)
$$

Step 5. For each consensus profile $\left.\mathrm{CPB}_{\mathrm{m}}^{\mathrm{a}}\left(\mathrm{t}_{\mathrm{c}}\right) \in \mathrm{CPB}^{\mathrm{A}^{\prime}} \mathrm{t}_{\mathrm{r}}\right)$ compute the value of coefficient $\alpha_{a}, a \in A^{\prime}$ and chose those agents as the most knowledge richest and reliable for which the coefficient $\alpha_{a}$ is maximal.

$$
\alpha_{\mathrm{a}}=\frac{\mathrm{D}_{\mathrm{a}}^{\mathrm{MC}}+1}{\mathrm{D}_{\mathrm{a}}^{\mathrm{CM}}+1}
$$

Remark 4. Two factors have an influence on the value of coefficient $\alpha_{\mathrm{a}}$. The closure of an particular consensus profile $\mathrm{CPB}^{\mathrm{a}}{ }_{\mathrm{m}}\left(\mathrm{t}_{\mathrm{c}}\right) \in \mathrm{CPB}^{\mathrm{A}}{ }_{\mathrm{r}}\left(\mathrm{t}_{\mathrm{c}}\right)$ to the median profile $\operatorname{Med}^{\mathrm{A}^{\prime}}\left(\mathrm{t}_{\mathrm{c}}\right)$, $\mathrm{r} \in\{1,2, \ldots, 6\}$ (Step 3 of KRRA)and the information power of a particular consensus profile $\mathrm{CPB}_{\mathrm{m}}^{\mathrm{a}}\left(\mathrm{t}_{\mathrm{c}}\right)$ understood by means of the cardinality of objects, which states are known for an agent $\mathrm{a} \in \mathrm{A}^{\prime}$ in this consensus profile (Step 4 of KRRA). Let us note that the value $\mathrm{D}^{\mathrm{MC}}$ a should be minimal. It means that the agent with the cognitive range closed to cognitive range of other agents' is needed. On the other hand the value $\mathrm{D}^{\mathrm{CM}} \mathrm{a}$ should be maximal. In this case the scope of agent's cognition is taken into account. The important is that only known states of objects are taken into account. As a consequence the objects from agents' area incompetence are omitted. 


\subsection{Computational Example}

Let the external world $\mathrm{W}$ consist of atom objects $\mathrm{O}=\left\{\mathrm{o}_{1}, \mathrm{o}_{2}, \mathrm{O}_{2}, \ldots \mathrm{o}_{11}\right\}$. At the time point $\mathrm{t}_{12}$ the state of an object $\mathrm{o}_{1}$ in relation to the properties $\mathrm{P}_{1}$ and $\mathrm{P}_{2}$ is not known for the agents $A^{\prime}=\left\{a_{1}, a_{2}, a_{5}, a_{7}\right\} \subseteq A=\left\{o_{1}, o_{2}, \ldots, o_{20}\right\}$. After applying the algorithm for the choice of relevant semantic messages the agents generate the messages $B=\left\{B^{a}\left(P_{i}(0) \wedge P_{j}(0)\right)\right.$ : $\mathrm{a}=1,2,5,7\}$. Let apply the KRRA algorithm:

Step 1. The set $\mathrm{CPB}^{\mathrm{A}^{\prime}}{ }_{1}\left(\mathrm{t}_{12}\right)=\left\{\mathrm{CBP}_{1}^{1}\left(\mathrm{t}_{12}\right), \mathrm{CBP}^{2}{ }_{1}\left(\mathrm{t}_{12}\right) \mathrm{CBP}_{1}^{5}\left(\mathrm{t}_{12}\right) \mathrm{CBP}_{1}{ }_{1}\left(\mathrm{t}_{12}\right)\right\}$, where: $\mathrm{CBP}_{1}^{1}\left(\mathrm{t}_{12}\right)=\left\{\left\{\mathrm{o}_{1}, \mathrm{O}_{2}\right\},\left\{\mathrm{o}_{3}, \mathrm{o}_{4}, \mathrm{o}_{5}\right\},\left\{\mathrm{o}_{6}, \mathrm{o}_{7}, \mathrm{o}_{8}, \mathrm{o}_{9}, \mathrm{o}_{10}\right\} ;\left\{\mathrm{o}_{1}, \mathrm{o}_{3}, \mathrm{o}_{4}\right\},\left\{\mathrm{o}_{5}, \mathrm{o}_{7}, \mathrm{o}_{9}\right\},\left\{\mathrm{o}_{2}, \mathrm{o}_{6}, \mathrm{o}_{8}, \mathrm{o}_{10}\right\}\right\}$ $\mathrm{CBP}^{2}{ }_{1}\left(\mathrm{t}_{12}\right)=\left\{\left\{\mathrm{o}_{1}, \mathrm{o}_{2}, \mathrm{o}_{7}\right\},\left\{\mathrm{o}_{3}, \mathrm{o}_{4}, \mathrm{o}_{8}, \mathrm{o}_{10}\right\},\left\{\mathrm{o}_{5}, \mathrm{o}_{6}, \mathrm{o}_{9}\right\} ;\left\{\mathrm{o}_{1}, \mathrm{o}_{3}, \mathrm{o}_{4}, \mathrm{o}_{6}\right\},\left\{\mathrm{o}_{5}, \mathrm{o}_{7}, \mathrm{o}_{9}\right\},\left\{\mathrm{o}_{2}, \mathrm{o}_{8}, \mathrm{o}_{10}\right\}\right\}$ $\mathrm{CBP}_{1}^{5}\left(\mathrm{t}_{12}\right)=\left\{\left\{\mathrm{o}_{1}\right\},\left\{\mathrm{o}_{3}, \mathrm{o}_{8}, \mathrm{o}_{9}\right\},\left\{\mathrm{o}_{2}, \mathrm{o}_{4}, \mathrm{o}_{5}, \mathrm{o}_{6}, \mathrm{o}_{7}, \mathrm{o}_{10}\right\} ;\left\{\mathrm{o}_{1}, \mathrm{o}_{3}, \mathrm{o}_{4}\right\},\left\{\mathrm{o}_{6}, \mathrm{o}_{7}, \mathrm{o}_{9}\right\},\left\{\mathrm{o}_{2}, \mathrm{o}_{5}, \mathrm{o}_{8}, \mathrm{o}_{10}\right\}\right\}$ $\mathrm{CBP}_{1}^{7}\left(\mathrm{t}_{12}\right)=\left\{\left\{\mathrm{o}_{1}, \mathrm{o}_{2}\right\},\left\{\mathrm{o}_{3}, \mathrm{o}_{4}, \mathrm{o}_{6}\right\},\left\{\mathrm{o}_{5}, \mathrm{o}_{7}, \mathrm{o}_{8}, \mathrm{o}_{9}, \mathrm{o}_{10}\right\} ;\left\{\mathrm{o}_{1}, \mathrm{o}_{3}\right\},\left\{\mathrm{o}_{5}, \mathrm{o}_{7}, \mathrm{o}_{10}\right\},\left\{\mathrm{o}_{2}, \mathrm{o}_{4}, \mathrm{o}_{6}, \mathrm{o}_{8}, \mathrm{o}_{9}\right\}\right\}$

Step 2. The median profile for the set $\mathrm{CPB}^{\mathrm{A}}{ }_{1}\left(\mathrm{t}_{12}\right)$ is equal:

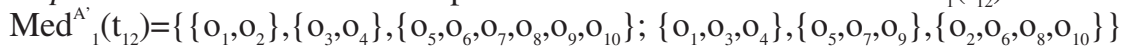

Step 3. For each consensus profile $\mathrm{CPB}_{1}^{\mathrm{a}}\left(\mathrm{t}_{12}\right) \in \mathrm{CPB}^{\mathrm{A}^{\prime}}\left(\mathrm{t}_{12}\right) \mathrm{D}^{\mathrm{MC}}$ is equal: $\mathrm{D}_{1}^{\mathrm{MC}}=0$, $\mathrm{D}_{2}^{\mathrm{MC}}=0, \mathrm{D}^{\mathrm{MC}}=3, \mathrm{D}^{\mathrm{MC}}=1$.

Step 4. For each consensus profile $\mathrm{CPB}_{1}^{\mathrm{a}}\left(\mathrm{t}_{12}\right) \in \mathrm{CPB}^{\mathrm{A}^{\prime}}\left(\mathrm{t}_{12}\right) \mathrm{D}^{\mathrm{CM}}$ is equal: $\mathrm{D}_{1}^{\mathrm{CM}}=1$, $\mathrm{D}_{2}^{\mathrm{CM}}=4, \mathrm{D}^{\mathrm{CM}}=3, \mathrm{D}^{\mathrm{CM}}=2$.

Step 5. The values of coefficient $\alpha_{a}$ are: $\alpha_{1}=2, \alpha_{2}=5, \alpha_{5}=1, \alpha_{7}=1.5$. The most knowledge richest and reliable is agent $\mathrm{a}_{2}$.

\section{Conclusions}

Although the symbol grounding problem has been studied for quite a long time, there is still a lack of mathematical models for simplest languages' grounding [11].

The aim of this paper was to investigate the level of grounding the belief formulas generated individually by the agents in multiagent system after applying the algorithm for the choice of relevant messages. The semantic closeness of the messages was investigated. A method for computing the set of agents with the maximal cognitive capacity to observe the states of objects and maximal similarity of knowledge states to the median state of knowledge of all agents in a system was presented.

\section{References}

1. Daniłowicz, C., Nguyen, N. T.: Consensus-based Partition in the Space of Ordered Partitions. Pattern Recognition, 3, (1988) 269-273

2. Dennett, D.C.: Kinds of Minds. Basic Books, New York (1996) 
3. Fauconier, G.: Mappings in Thought and Language. Cambridge University Press, Cambridge (1997)

4. Harnad, S.:The Symbol Grounding Problem. Physica, 42, 335-236

5. Katarzyniak, R.: Defining the Relation between Intentional and Implementation-oriented Levels of Agents Models. In: Proc. of ISAT'2000, Szklarska Poręba, (2000), 208-216

6. Katarzyniak, R., Nguyen, N.T.: Reconciling Inconsistent Profiles of Agents' Knowledge States in Distributed Multiagent Systems Using Consensus Methods. Systems Science, Vol. 26 No. 4, (2000) 93-119.

7. Katarzyniak, R., Pieczyńska-Kuchtiak, A.: Formal Modeling of the Semantics for Communication Languages in Systems of Believable Agents. In: Proc. of ISAT'2001, Szklarska Poręba, (2001), 174-181

8. Katarzyniak, R., Pieczyńska-Kuchtiak, A.: Intentional Semantics for Logic Disjunctions, Alternatives and Cognitive agent's Belief. In: Proc. of the $14^{\text {th }}$ International Conference on System Science, Wrocław, Poland, (2001), 370-382

9. Katarzyniak, R., Pieczyńska-Kuchtiak, A.: A Consensus Based Algorithm for Grounding Belief formulas in Internally Stored Perceptions. Neural Network World, 5, (2002) 671682

10. Katarzyniak, R., Pieczyńska-Kuchtiak, A.: Distance Measure Between Cognitive Agent's Stored Perceptions. In: Proc. of IASTED International Conference on Modelling, Identification and Control, MIC'2002, Innsbruck, Austria (2002) 517-522

11. Katarzyniak, R., Pieczyńska-Kuchtiak, A.: Grounding Languages in Cognitive Agents and Robots. In: Proc. of Sixteenth International Conference on System Engineering, Coventry (2003) 332-337

12. Pieczyńska-Kuchtiak, A.: A Decision Function in the Algorithm for the Choice of Semantic Messages. In: Proc. of Information Systems Architecture and Technology, Poland (2002)

13. Nguyen, N.T.: Consensus System for Solving Conflicts in Distributed Systems. Information Sciences, 147, (2002) 91-122 